\title{
Cuatro corporales atribuidos a Santa Clara de Asís
}

\section{INTRODUCCIÓN}

En el Monasterio de Santa Clara de Zamora se conservan dos corporales, y en el de Salamanca, de la misma Orden, otros dos que, según la tradición, fueron realizados por Santa Clara de Asís. Son cuatro piezas que estan sin documentar de forma directa por lo que para probar su autenticidad hay que recurrir a medios indirectos y a las claves estructurales de los propios corporales. Entre los primeros se encuentran algunas citas escritas y la comprobación de que los Monasterios de Zamora y Salamanca se fundaron en fechas en que aún vivía la Santa seráfica y pudieron llegar a ellos dichos corporales. Las claves estructurales se basarán en el estudio de las propias piezas.

Consta por testimonios evidentes que Santa Clara, durante su larga enfermedad, se dedicó a hilar y que hilaba telas finísimas, de las cuales se confeccionaron varios corporales ${ }^{1}$. Así, Sor Cecilia de Spello, después de explicar, en el proceso de canonización, cómo la santa, estando enferma, se dedicaba a hilar, añade que "de este hilado mandó confeccionar una tela fina con la que se hicieron muchos corporales y fundas para guardarlos, guarnecidas de seda o de paño precioso..." ${ }^{2}$. Y Sor Francisca de Messer Capitaneo de Col de Mezzo, en su declaración, atestigua que ella misma contó cincuenta pares de corporales, los cuales fueron distribuidos a diversas iglesias ${ }^{3}$. Testimonios parecidos rinden también Sor Pacífica de Guelfuccio y Sor Bienvenida de Perusa. Alejandro IV, en la bula de canonización, confirma que la Seráfica Madre ordenó que se hicieran

1 Los testimonios están recogidos en Escritos de Santa Clara y Documentos complementarios, Edición bilingüe preparada por Ignacio Omaechevarría, OFM, 2. ${ }^{\text {a }}$ edic. ampliada, (Madrid: BAC, 1982). Véanse particularmente las declaraciones de Sor Pacífica de Guelfuccio, Sor Bienvenida de Perusa, Sor Cecilia de Spello y Sor Francisca de Messer Capitaneo de Col de Mezzo en el Proceso de Canonización de Santa Clara (pp. 60-115); y el del Papa Alejandro IV, en la Bula de Canonización (pp. 115-127). También de fray Tomás de Celano, en la Legenda Sancta Clarae (pp. 127-197).

2 I. OMAeCheVARría, Escritos de Santa Clara y Documentos..., p. 91.

3 Idem, p. 98. 
(fieri fecit), de la tela de lino preparada con su labor y arte, muchos corporales para el sacrificio del altar y que se distribuyeran a diversas iglesias del valle y de la montaña ${ }^{4}$. La Legenda Sanctae Clarae, núm. 28, concluye:

durante aquella larga enfermedad que la tuvo postrada en cama, se hacía incorporar y asentar al apoyo de unas almohadas; y así sentada, hilaba finísimas telas, de las cuales se elaboraron más de cincuenta pares de corporales, que, envueltos en fundas de seda o púrpura, se distribuían por diversas iglesias del valle y de las montañas de Asís... 5 .

Todas estas citas confirman claramente que Santa Clara intervino en la manufactura de los corporales, al menos, en la fase del hilado del lino.

\section{Fundación de los Monasterios de SANTA Clara de las ciudades de ZAMORA Y DE SALAMANCA}

Los Monasterios medievales de Damianitas —que así se llamaban las Clarisas en un principio- tienen frecuentemente, además de su historia propiamente dicha, una especie de prehistoria, no suficientemente documentada y no siempre del todo concorde con la documentación histórica disponible, aunque no por ello es menos digna de atención para una inteligencia más completa y exacta de los orígenes de dichos monasterios.

Así en España, los monasterios de Burgos, Salamanca, Zamora, Ciudad Rodrigo, Carrión de los Condes, Medina del Campo, Valladolid, Cuéllar y Toledo sostienen haber sido fundados por discípulas o compañeras de Santa Clara, o aún por sobrinas y primas suyas, en los años 1218, 1224, $1229,1230,1231,1238,1244$ ó 1250. Desde luego, teniendo en cuenta lo que conocemos de la familia de la Santa y de las monjas de su comunidad de San Damián de Asís, podemos asegurar que en general no se trata de parientes de la hija de Favarone de Offreduccio, ni de Hermanas de su monasterio quienes fundaron estos monasterios españoles, sino mujeres "beatas" españolas que acuden en peregrinación a Roma y a Asís, y no tan sólo por visitar las tumbas de los Apostóles San Pedro y San Pablo, sino porque han oído hablar de la vida ejemplar de las "Damianitas" por boca principalmente de los Frailes Menores que van fundando conventos por todas partes. Allí, en Asís, estas "beatas" visitan a la Seráfica Madre, de quien aprenden el nuevo modo de vida contemplativa religiosa, y se

4 Idem, pp. 122-123.

s Idem, p. 163. 
hacen, en cierto modo, "discípulas". De esta manera, surgen las fundaciones de Cuéllar, Tudela, Medina del Campo, Todos los Santos (actualmente, Santa Clara) de Valladolid, San Francisco (actualmente, Santa Clara) de Zamora, Santa María (hoy Santa Clara) de Burgos, Santa Catalina de Zaragoza, Santa María de Salamanca y otros.

Parece que por los años 1218 a 1250 hubo un intenso movimiento de peregrinaciones de este tipo entre España e Italia. De hecho, la bula Ille dulcissimus, de Gregorio IX, de 13 de abril de 1234, menciona, para la fundación de Burgos, los nombres de las cuatro "beatas" burgalesas, María Sánchez, María Mínguez, Juliana y Toda, que llegan a Roma en peregrinación y vuelven con el documento pontificio que las autoriza a constituirse en comunidad de la Orden de San Damián, eligiendo abadesa a una de ellas... ${ }^{6}$.

Cosa parecida pudo ocurrir en Carrión de los Condes, cuya primera fundación se habría llevado a cabo, según tradición local, en 1231, en Santa María del Páramo, si bien extraña que no aparezca hasta veinticinco años más tarde el primer documento conocido referente al caso, la bula In multam redundat, dada en Anagni a 3 de junio de 1256, que por lo demás supone ya existente en Santa María del Páramo una comunidad de Damianitas (Ordinis Sancti Damiani), cuyo traslado a Carrión se autoriza en la fecha citada ${ }^{7}$. Una interpretación de este género cabría también para Medina del Campo, donde las discípulas de Santa Clara, fundadoras del Monasterio, enterradas junto a la reja del coro, serían, más bien, las siervas de Dios, Francisca de Bracamonte e Inés de Ortega ${ }^{8}$.

Otro tanto puede suponerse, asimismo, para el caso de Zamora, cuyo monasterio remontaría, según la tradición, al año 1229. Por varios breves de 1237 consta que en la citada fecha funcionaba ya, no sabemos desde cuando (¿desde 1229?), una comunidad de hermanas o sores de la "Orden de San Damián", presidida por una tal Dominica o Dominga, quien tal vez viajó a Roma con alguna compañera de su beaterio y volvió a España trayendo consigo los Breves Pontificios de 1237 y algunos recuerdos de Asís, entre ellos un par de corporales tejidos por Santa Clara, que se

6 Para los monasterios que pretendían haber sido fundados por compañeras o discípulas de Santa Clara, véase mi trabajo Las clarisas a través de los siglos, especialmente en p. 55, nota 2, y Primeros monasterios de Clarisas en España (Ediciones Santa Clara (Soria, Ed. Santa Clara, Colec. "Espíritu y Vida", núm. 3).

7 La Bula original se conserva en el archivo del Monasterio de Carrión de los Condes (Palencia).

8 Puede consultarse el Libro Becerro en el Monasterio de Santa Clara de Medina del Campo (Valladolid). 
conservan con gran veneración en el actual monasterio zamorano 9 . En todo caso, la fundación del Monasterio de Damianitas de Zamora se formalizó en 1237 bajo el título de San Francisco de los Arenales o Arnales. Se trata de siete Breves Pontificios, el primero de ellos fechado en 20 de octubre, y el último, en 11 de diciembre. Los cuatro primeros Breves están dirigidos a las "Amadas Hijas en Cristo, Dominga y demás Hermanas del monasterio de Arnales de Zamora, de la Orden de San Damián" (Dilectis in Christo filiabus Dominicae ac aliis sororibus monasterii de Arnales in Zamoren. dioc [...] Ordinis Sancti Damiani). Por el quinto de los Breves, Quoniam ut ait Apostolus, de 20 de noviembre de 1237, Gregorio IX exhorta a los fieles de la ciudad y diócesis de Zamora a que contribuyan con sus limosnas a la construcción del monasterio; y por el sexto, Cum sicut ex parte, de 11 de diciembre del mismo año, el Papa ordena al Ministro (que en esa fecha no es necesariamente el Ministro Provincial, sino que puede ser el Ministro local o Guardián) de los Frailes Menores de Zamora que señale dos frailes idóneos de la Orden para que dirijan las obras de construcción del monasterio. Finalmente, el séptimo Breve, Quia Spiritus, igualmente de 11 de diciembre, se dirige no ya simplemente a "Dominga y demás hermanas", sino a las "amadas hijas Abadesa y hermanas encerradas" (dilectis in Christo filiabus Abbatissae et sororibus inclusis) del monasterio de Arnales de Zamora, de la Orden de San Damián.

Conviene analizar el contenido de cada uno de estos Breves. Por el Devotionis vestrae (20 de octubre de 1237) se concede la facultad para que Dominga y sus hermanas construyan una capilla con su campanario, etc. Por el Auctoritate vobis (20 de octubre de 1237) se les faculta para que puedan elegir abadesa. Por el Iustis petentium desideriis (22 de octubre de 1237) se establece en la nueva fundación el orden monástico según la Regla de San Benito y los Estatutos de la Orden de San Damián de Asís, Regla del Cardenal Hugolino, y se toma el monasterio con todos sus bienes presentes y futuros, ...sub Sancti Petri et Nostra protectione. Por el Vestris precibus (20 de noviembre de 1237 ) se les autoriza a comprar terrenos para edificar el monasterio. Finalmente, por el Breve Quia Spiritus (11 de diciembre de 1237), suponiéndose elegida ya la abadesa y establecida la clausura, se concede a la nueva comunidad ...ut liceat vobis mulieres $l i$ -

9 Los siete Breves de Gregorio IX, desconocidos para Gonzaga, Wadding y Sbaralca, como también para los cronistas e historiadores clásicos, se conservan en el Archivo de la Catedral de Zamora y no en el del Monasterio. Por lo visto, la Madre Dominga los debió consignar al obispo para su ejecución y de este modo quedaron depositados en la catedral. 
beras et absolutas ex saeculo fugientes, ad conversionem recipere ac eas absque contradictione aliqua retinere...

Gonzaga (1587) cita, del Archivo del Monasterio de Santa Clara de Zamora, diversas Bulas: del 5 de Abril de 1243, 11 de abril 1244, 24 de octubre de 1244, 23 de enero de $1255 \ldots$ En el Bulario franciscano y en el Registro de Wadding se encuentran las tres Bulas siguientes de Inocencio IV: a) Divinae affluentia, del 17 de agosto de 1243 , por la que se conceden algunas mitigaciones respecto al ayuno y abstinencias prescritas por la Regla del Cardenal Hugolino, profesada desde el principio por las monjas; b) Cum sicut ex parte vestra, del 2 de junio de 1246, que se expide con el mismo tenor para catorce monasterios, de Italia, Francia y España, entre ellos para el de Zamora, donde se concreta el modo en que los monasterios de las Damianitas deberán ser confiados a la jurisdicción de los Frailes Menores ${ }^{10}$; c) Apostolicae Sedis benignitas, del 9 de febrero de 1253 , no registrada por Wadding, donde se atribuye a las monjas de Zamora la extraña declaración de que ellas, hasta la fecha, "no han profesado ninguna Orden" (nullum adhuc Ordinem sunt professae). Pero no parece que pueda afirmarse que no formaran parte de la "Orden de las Monjas Encerradas de San Damián", ya que algunas de las Bulas precedentes están dirigidas precisamente: Dilectis in Christo filiabus Abbatissae et Conventui Monialium Inclusarum Monasterii Sancti Francisci de Arnales, Zamorensis Diocesis, Ordinis Sancti Damiani. Entre las Bulas referentes al monasterio de Santa Clara de Zamora se ha de señalar también una de Martino V: Habentes in desiderio cordis, de 13 de noviembre de 1423 (...Dilectis in Christo filiabus Abbatisae et conventui Monialium Sancte Clarae Zamoren.), que se conserva en el Archivo de Santa Clara de Tordesillas, y en cuya virtud también el monasterio de Zamora queda afiliado a la familia o federación de Tordesillas ${ }^{11}$.

Para la historia de la fundación del Monasterio de Clarisas de Salamanca existe también una importante documentación por la que se sabe que "beatas" con nombres y apellidos españoles como María Sánchez, María Mínguez, Francisca de Bracamonte, Inés de Ortega, Dominga, Toda

10 Véase mi estudio, "La Regla y las Reglas en la Orden de Santa Clara", Cuadernos Franciscanos, 46 (1976), pp. 110-116.

11 Todas estas fundaciones en sus orígenes tomaron la forma de simples beaterios, registrados en algunos casos como formando parte de la Orden de San Damián. Pero esta situación no es exclusiva de España, pues aún fuera, se dan casos, como el de Sor Ermentrudis de Colonia, fundadora del Monasterio de Brujas en Flandes, a la que Clara de Asís debió de escribir un par de cartas y que también peregrinó a Asís, aunque, según parece, no llegó ya a ver a la Santa. Ver I. OMAECHEVARRía, Escritos de Santa Clara y documentos... pp. 398 y 399. 
y hasta Urraca pertenecieron al Monasterio de esta ciudad. Y fue Urraca la que debió desplazarse a Asís y Roma, regresando de allí con una copia de la Regla del cardenal Hugolino y con diversas reliquias: la calavera de San Gilberto o San Alberto mártir, algunas guedejas de la cabellera de Santa Clara y un juego de corporales confeccionados por la santa... ${ }^{12}$. Según las tradiciones recogidas por nuestros cronistas, el eremitorio o beaterio de Santa María de Salamanca se remontaría a 1220. Doña Urraca, fundadora de dicho eremitorio, debió ir en peregrinación a Italia con otra hermana en 1237. En este mismo año parece que también fue la Madre Dominga de Zamora ${ }^{13}$. En efecto, la primera bula actualmente conocida, relativa al Monasterio de Santa Clara de Salamanca, Ad nostram noveris, dirigida por Gregorio IX al rey de Castilla Don Fernando III el Santo, es de 4 de enero de 1238. Pero por el tenor de las bulas sucesivas se deduce que hubo algún documento anterior, a saber, otra bula con la Regla del Cardenal Hugolino, que al parecer doña Urraca trajo consigo desde Roma. Acerca de la historia del Monasterio de Salamanca nos remitimos al magnífico estudio del P. Isaac Vázquez ${ }^{14}$.

Podemos concluir diciendo que las fundaciones de los monasterios de Zamora y Salamanca, de religiosas clarisas, se hicieron en vida de la Santa y que probablemente fueron discípulas españolas las que, en contacto con

12 Ciertamente, la primera impresión que produce la relación de semejantes reliquias es la de un prudente escepticismo; pero no podemos darnos por satisfechos con observar que resulta muy extraña la pretendida calavera de San Alberto o San Gilberto mártir, de nombre germánico, no asimilado aún por la cultura grecorromana durante el período de las persecuciones; como también resulta extraño que la propia Santa Clara regalara a sus nuevas discipulas algunas guedejas de su cabellera. No basta rechazar simplemente la autenticidad de las reliquias, mientras no demos alguna explicación aceptable del fundamento histórico que subyace en la leyenda. Podríamos preguntarnos, por ejemplo, si la citada calavera, más bien que de un mártir romano, no sería la del patriarca San Alberto de Jerusalén, quien redactó la Regla primera de los eremitas del Monte Carmelo, los cuales por entonces, saliendo del Oriente, se establecieron en varias naciones de Europa. Por lo que respecta a los cabellos de Santa Clara, si se pretende que fueran parte de los que San Francisco le cortó en la Porciúncula, al principio de su conversión, no lo creemos tan fácilmente. Pero si advertimos que la Santa, después de aquella primera tonsura, hubo de someterse a otras sucesivas, ¿no es natural que las hermanas tonsoras conservaran por devoción algunos bucles, como algunos de los compañeros de San Francisco, por ejemplo, trataban de conservar piadosamente las uñas de los pies del Seráfico Patriarca?

is Véase mi estudio "Origini del Monasterio di Santa Chiara di Zamora", Forma Sororum, 21 (1984), pp. 45-52.

it Isaac VAzQuez, Documentación Pontificia Medieval en Santa Clara de Salamanca. Un suplemento al Bullarium Franciscanum., Studia Histórico-Ecclesiástica. Festgabe für Prof. Luchesius G. Spätling OFM, pp. 347-418. 
la casa generalicia de Asís, hicieron posible tales fundaciones. Por lo tanto, las relaciones de los conventos de España con los de Asís son patentes, en la Orden de las Damianitas o Clarisas.

\section{Claves estructurales}

Todo objeto se transforma en documento histórico de sí mismo y de la época a que pertenece, pues posee unas claves constitutivas de su estructura, a través de las cuales descubrimos diversos factores como la materia, la técnica, la función, la ornamentación, el simbolismo, etc. Es decir, todo objeto surgido como consecuencia de unas relaciones humanas con su entorno social e histórico es un verdadero testigo de ellas. Los historiadores puristas recelan de todo objeto que no vaya documentado con avales escritos. Pero la mayor parte de los objetos de uso cotidiano han llegado a nosotros sin documentación añadida, teniendo que enfrentarnos al propio objeto por medio del método analítico, tomando como elementos de referencia, cuando existen, otros datos contrastados y afirmados con anterioridad por estudios de un mayor rigor ciéntifico. Pero cuando un objeto carece de refrendos escritos es exigible, por parte del investigador, que sea especialista en la materia para que pueda interpretar, con el menor error posible, los mensajes que ofrecen los elementos constitutivos de su realidad plástica. Y con todo, pueden quedar ciertas lagunas que podrían resolverse con el tiempo o, en algunos casos, resultar insalvables. En los corporales custodiados en los Monasterios de Clarisas de las Ciudades de Zamora y Salamanca, objeto del presente estudio, vamos a analizar los siguientes elementos: denominación, materia, forma, tamaño, técnica, función, ornamentación y simbolismo, utilizando el método comparativo para comprobar analogías y diferencias que nos permitan verificar si son de la misma época y procedencia.

1.-Denominación. La denominación de corporales en plural se usa frecuentemente, aunque se haga referencia a una sola pieza. Esta costumbre persiste por inercia, porque en tiempos pasados solían ser dos los que se utilizaban en la celebración de la misa. En inventarios eclesiásticos generalmente se citan por pares y rara vez aparece reseñado solamente uno.

El término de corporales se documenta en España, cuando menos, desde el siglo x. El documento más antiguo conocido se fecha en el 957, año en que murió Vadimiro, obispo de Vich, en cuyo inventario, entre sus pertenencias sacerdotales, se citan cinco corporales. En el inventario de la catedral de Salamanca de 1257 se citan dos corporales. En el de Santo 
Toribio de Liébana de 1360 se recogen las citas de: "Item. unos corporales nobles con su caja de seda festivales [...] Item. tres aras con sus corporales en los altaresn. En el inventario de la Capilla del Condestable (Burgos), de 1585 , los corporales que se citan pasan de un centenar ${ }^{15}$. Villanueva ${ }^{16}$ utiliza el vocablo fanon aplicado indistintamente a los ornamentos conocidos como corporal y manípulo, también lo da como equivalente al de bandera ${ }^{17}$. La voz de fanon es habitual en inventarios eclesiásticos medievales apareciendo junto a la palabra estola y con función de complemento de la misma, por lo que, en la mayoría de los casos, representa al manípulo; en menos ocasiones puede representar al corporal propiamente dicho. También hay que señalar que fanon es término más frecuente en inventarios de iglesias de los condados catalanes, y corporal aparece muchas más veces en los de los templos castellanos. Corporal, corporale y korporale son términos utilizados, desde el siglo $\mathrm{xv}$, en diversos países europeos para designar la misma pieza ritual en las ceremonias religiosas cristianas, un mantelito de altar para cubrir el ara.

2.-Materia. Este factor hace referencia a la naturaleza de que está compuesto el objeto, referente a su origen material. Los cuatro corporales custodiados en los Monasterios de Clarisas de las ciudades de Zamora y Salamanca están realizados en lino. Este tejido fue, en el origen de las ceremonias litúrgicas, uno de los más utilizados. Existen suficientes noticias históricas que afirman cómo el lino se aplicó, desde muy antiguo, en ceremonias sagradas. Está fuera de duda que los datos obtenidos de las Sagradas Escrituras confirman que entre los judíos se usaron tejidos de lino retorcido (retorto) en su color natural (crudo) o en un tono marfileño cuando había sido blanqueado. Igualmente, el lino se utilizó teñido en varios colores y ornamentado con recamos ${ }^{18}$. Para las vestiduras sagradas de Aarón se aplicó el lino muy fino; para el efod y el pectoral se emplearía el hilo torzal de lino ${ }^{19}$.

El lino blanco, de la más fina calidad, se ha venido aplicando a ciertas vestiduras litúrgicas como albas, amitos y roquetes, aunque se sabe que,

${ }^{15}$ Antolín P. Villanteva, Los omamentos Sagrados en España, (Barcelona: Labor, 1935). p. 120.

16 Op. cit.. Glosario. p. 327.

1- Algunos diccionarios dan como equivalente de fanon un ornamento en forma de doble esclavina cerrada, con la inferior más larga, que lleva el papa sobre el alba en la misa pontifical.

18 Éxodo, cap. XXVI y XXXVI.

19 Éxodo, cap. XXVIII, v. 2, 4, 6, 9, 15, 17, y 40. 
desde el siglo IV al IX, los ornamentos sagrados eran todos blancos (habitus religionis). Después del siglo $\mathrm{xI}$, la Iglesia admitió los cinco colores litúrgicos actualmente vigentes. Pero de forma esencial, los llamados paños de altar siempre han sido de lino: sabanillas, purificadores, corporales, etc., manteles de diversos tamaños fueron usados desde los primeros tiempos de la liturgia cristiana. En inventarios de templos españoles, que datan de la época medieval, existen distintos vocablos para designarlos.

Para la confección de los corporales, según referencias de inventarios, se han venido utilizando diversos géneros de tejido de lino: calicud, ruan, cambrai, holanda y otro sin determinar que bien pudiera ser el conocido actualmente como lino cesero que era el género que se hacía en cada localidad con medios rurales y sencillos ${ }^{20}$.

Aunque la calidad de cada uno de los tejidos de lino con que se han confeccionado estos cuatro corporales que venimos estudiando la analizo en el punto siguiente, señalo que el análisis microscópico de fibras solamente ha podido realizarse para uno de los corporales del Monasterio de Salamanca, el signado con la letra $D$ en el punto siguiente del presente estudio, ya que solamente de él me fue suministrado un pequeño fragmento. Aplicando un microscopio Polyvar (Reichter-Jung) equipado con cámara fotográfica, la óptica utilizada ha sido un objetivo de 250 aumentos para luz trasmitida; el resultado obtenido ha sido el siguiente: en la prueba utilizada para la urdimbre dio que la fibra empleada era lino; en la prueba aplicada para la trama, dio igualmente la calidad de lino, por lo que puede concluirse que la materia con la que se ha confeccionado es de lino puro al cien por cien. De los otros tres corporales no fue posible obtener ningún fragmento, pero por las características texturales y plásticas observadas con el tacto y la vista podemos asegurar que están también confeccionados con materia de lino.

20 P. VillanueVa (op. cit. p. 230) relata que en el Monasterio del Escorial existió siempre gran acopio de corporales con hermosas labores de lienzos finísimos de calicud. ruan, cambrai y holanda, nombres de procedencia geográfica. Así, el calicud o calicó fue, en su origen, una tela delgada de algodón o seda manufacturada en la ciudad de Calicut, en la costa de Malabar. En España, el calicud fue un género en el que se mezclaba algodón y lino o lino y seda, ésta en una pequeña proporción. El ruán en su origen, fue también una tela de algodón estampada que se fabricaba en Rouen. Pero se hizo más famoso el tejido de algodón y lino blanco que tenía la misma procedencia e imitado en España. Este tejido se aplicaba a los ornamentos blancos, albas, roquetes y todo tipo de manteles, entre ellos los corporales. El cambrai es un lienzo blanco muy fino procedente de esa ciudad francesa. Es más sutil que la holanda y se imitó en España, aplicándose en ornamentos sagrados desde el siglo XVI. La holanda, oriunda de la ciudad belga que le da nombre, fue siempre un lienzo de lino empleado en prendas finas. Aparece en los ornamentos litúrgicos especialmente desde el siglo xv. También se fabricó en España en calidad similar a la de origen. 
En Italia, el uso del lino fue muy frecuente desde la Antigua Roma; aquí llegaron los exquisitos tejidos de lino procedentes de Egipto, aplicándose a piezas de indumentaria. Otro tanto sucedió en algunos países mediterráneos. La clase más fina de los linos egipcios se denominaba byssus y pronto fue imitada y reproducida en los países de importación. Los historiadores afirman que el lino de Italia era escaso y de mediana calidad, por lo que era muy apreciado el que llegaba de Egipto. Sin embargo, el lino se producía en Italia en las zonas rurales y se tejía localmente, siendo aplicado en diversos usos comunes y, ante todo, para ceremonias litúrgicas. No es de extrañar que Santa Clara hilase ya en la Edad Media lino para los corporales y otras prendas sagradas pues, en esta época, era una de las actividades propias de la mujer.

3.-Aspectos técnicos. Dentro de este apartado analizo el tipo de ligamento, las características estructurales del tejido (calidad, flexibilidad, elasticidad, resistencia y densidad) que vienen determinadas por el tipo de ligamento y el número de hilos en urdimbre, así como la homogeneidad de la hilada por la regularidad de su grosor y torsión. En ellos quedan integrados, también, los factores de tamaño y forma por surgir en la manufactura de los corporales. Al analizar los cuatro corporales o piezas, para un estudio ordenado y mejor distinción entre ellas, vamos a signar con las letras $A$ y $B$, respectivamente, los corporales del Monasterio de Santa Clara de Zamora ${ }^{21}$ y con las letras $C$ y $D$ los del Monasterio de Santa Clara de Salamanca.

Corporal $A$ (Monasterio de Zamora). Su ligamento es a la plana o de tafetán. Realizado el recuento de hilos "fine a fine" 22 nos proporciona un tendido total de 990 hilos aproximadamente, en una anchura final del lienzo que podría ser de 30 centímetros, medida muy común en la época medieval en tejidos utilizados para realizar pequeñas piezas. En detalle, este recuento nos da 33 hilos por centímetro lineal en la urdimbre y 25 hilos para la trama. Estamos ante un tejido de los denominados mienos o milenos porque su urdimbre alcanza o se acerca a los mil hilos. Se trata por su calidad de un género de cendal, emparentado con el mencionado byssus, de Egipto, Siria y Palestina y reproducido en países mediterrá-

21 Estos corporales de Zamora fueron estudiados y publicado su estudio en un artículo de Fr. Ignacio Omaechevarría y $\mathrm{M}^{2}$ Ángeles GonzÁlez Mena en Forma Sororum con el título de .Origini del Monasterio di Santa Chiara di Zamora. XXI (1984), pp. 45-52.

22 La expresión fine a fine, dentro del ámbito textil, hace referencia a la distancia o espacio comprendido entre los dos extremos que señalan el ancho o anchor de un tejido, espacio ocupado por el tendido de los urdimbres para formar la urdimbre. 


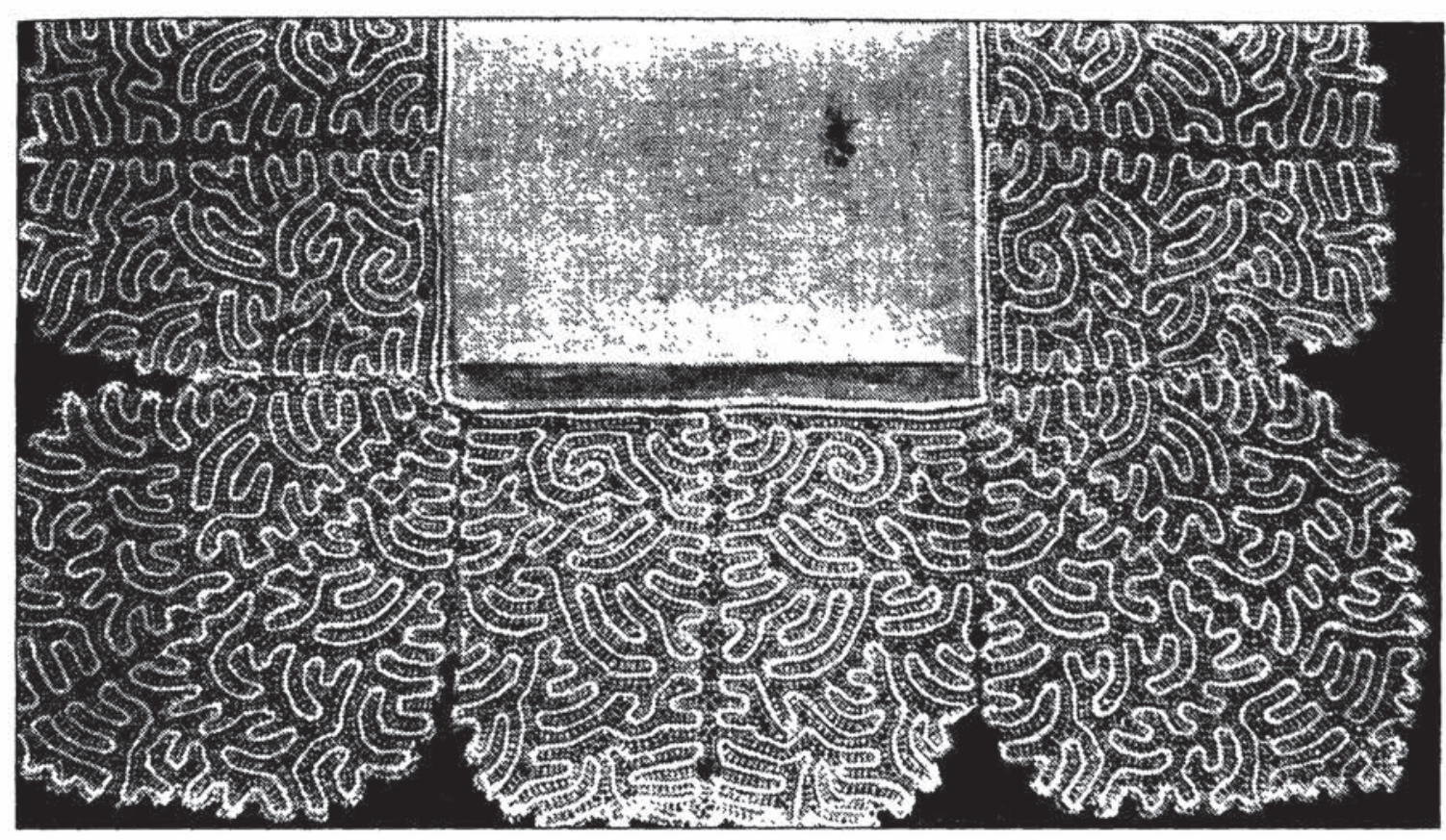

FIG. 1.-Encaje estilo "numérico" o de "doce bolillos" que adorna ambos corporales del Monasterio de Zamora ( $A$ y $B$ ). Realizado en lino blanco, es un modelo propio del siglo XVII, perteneciente a la escuela catalana.

neos ${ }^{23}$. El tipo de tejido de este corporal pudiera ser un género italiano medieval, derivado del egipcio y conocido con el nombre de arancia, similar al denominado en España por la misma época, rançan o escarin $y$, en ambientes populares, clarin ${ }^{24}$. Efectivamente, se trata de un tejido fino y claro, flexible y suelto. $\mathrm{El}$ indicador espacial o densidad viene representado por $0,033(30 / 900)$, espacio teórico ocupado por un hilo en el tendido de la urdimbre.

Corporal $B$ (Monasterio de Zamora). Consta de un cuadrado casi perfecto de tejido de lino $(27 \times 26 \mathrm{cms}$. $)$. El lino presenta unas características

23 En los países mediterráneos se imitaron las características del lino byssus: bien torcido, blando y de color crudo o natural, recibiendo diversos nombres según el lugar en que se producía. Del género byssus o bisso se recogen citas en inventarios del ajuar litúrgico empleado en las iglesias mozárabes en España, y se citan, de forma muy concreta, corporales de byssus (GOMEZ MORENO, Iglesias Mozárabes. Arte Español de los siglos IX al XI, Madrid, Centro de Estudios Históricos; 1919, p. 335).

24 El tejido de que está hecho este corporal puede identificarse con el tipo de cendales hispanos emparentados con los que se hacían en los países ribereños mediterráneos, entre ellos Italia, aquí los cendales recibían la denominación genérica de rançan que, al igual que los vocablos rancia y ranciarum, derivan de la italiana arancia. Importantes restos del género cendal se conservan en el Monasterio de las Huelgas (Burgos) procedentes de los enterramientos reales pertenecientes al siglo XIII (Gómez Moreno, El Panteón Real de las Huelgas de Burgos, Madrid: C.S.I.C., 1946). 


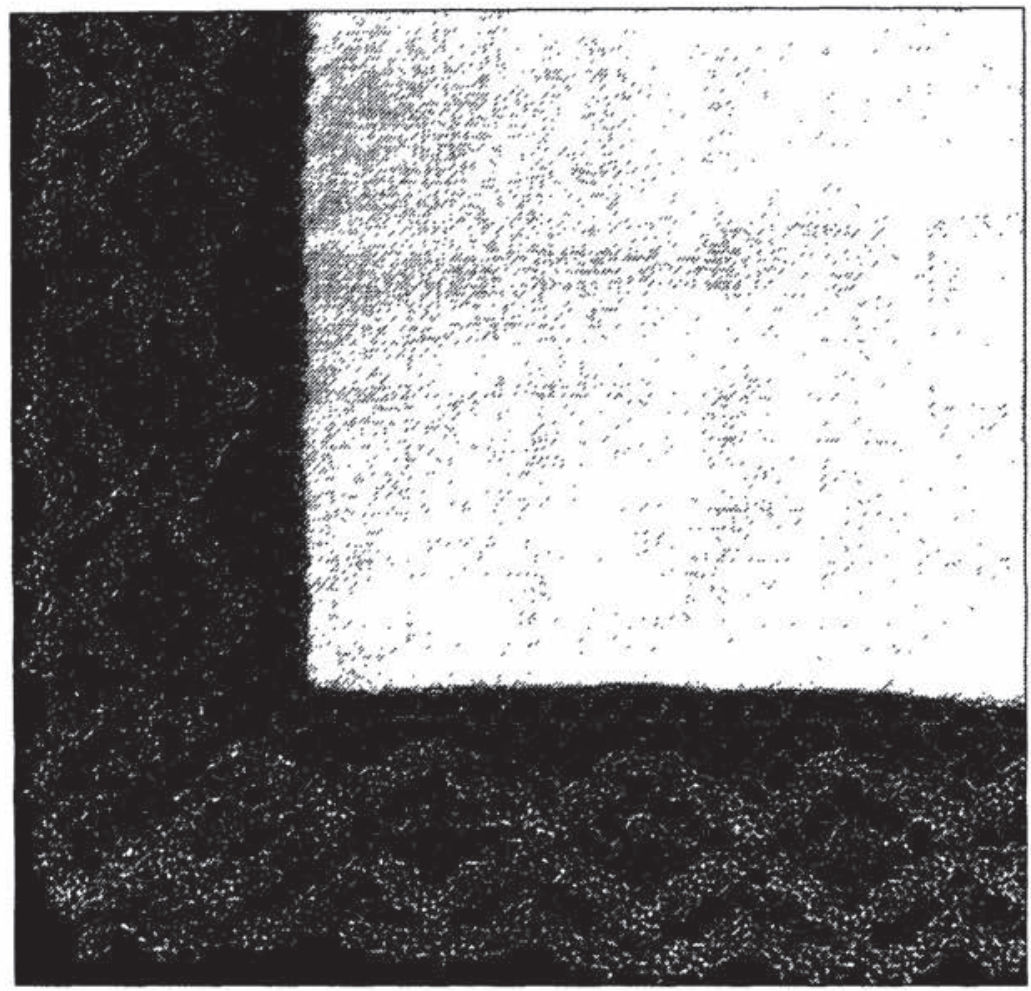

FIci. 2.-Encaje definitivo aplicado al corporal $C$, del Monasterio de Salamanca. Género "puntos de Fspanà, a bolillos con metal dorado. Reproduce un esquema castellano, estilo mudéjar, con espacios romboidales de lacería que albergan milanos.

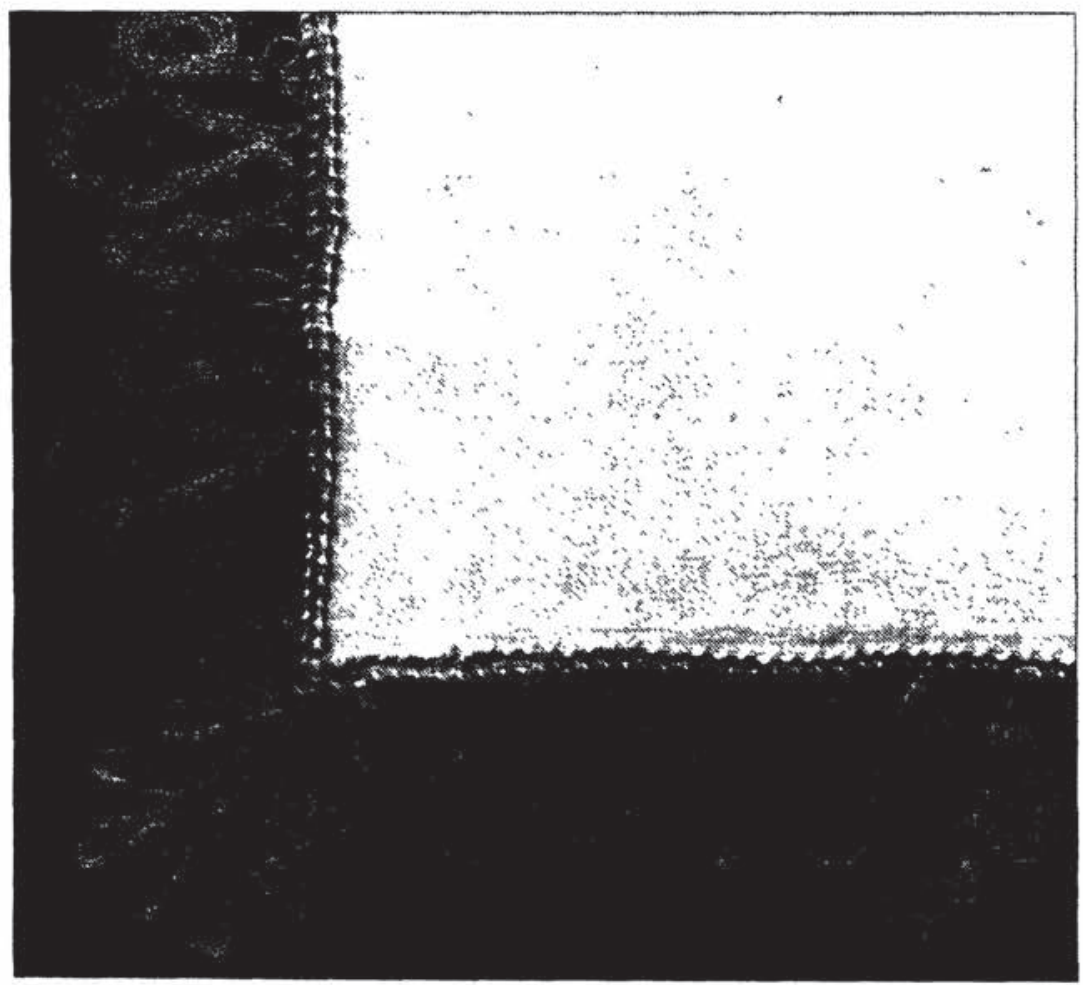

FIG. 3.-Encaje definitivo aplicado al corporal $D$, del Monasterio de Salamanca. Género "anillado de Valladolid", con técnica de aguja, sedas lasas de tonos suaves e hilillo metálico dorado. Reproduce un modelo antiguo de estilo renaciente. 
estructurales bien distintas al anterior. Si bien está realizado, igualmente, por un ligamento a la plana, se trata de un tejido que está regularmente tramado, muy tupido pero flexible, con poca torsión en la hilada, de brillo suave y de hilatura bastante homogénea, a excepción de algunos hilos gruesos que surcan ciertas zonas, debido a su hilatura manual. El recuento de los hilos proporciona 37 por centímetro lineal para la urdimbre y 34 para la trama. La pequeña diferencia de tres hilos a favor del tendido o urdimbre evidencia la calidad de este lino, de un tramado muy regular y casi perfecto. El indicador espacial para este género de tejido es de 0,029 (30/1020) aproximadamente.

Corporal C (Monasterio de Salamanca). Tiene forma rectangular $(36 \times 27 \mathrm{cms}$.). El tejido es de lino, de ligamento a la plana, de calidad semigruesa, de un tramado bastante regular y uniforme si se considera que el procedimiento técnico utilizado en la Edad Media empleaba únicamente la rueca y el huso para el hilado y un sencillo telar para el tejido. Presenta en algunas zonas ciertas irregularidades, perceptibles en un atento estudio de sus fibras, rasgos que son, en parte, un certificado de antigüedad, propios solamente en tejidos realizados manualmente y sin intervención de la máquina. Está bastante bien conservado, aunque se observan pequeñas roturas de hilos. La densidad del tejido de este corporal presenta un índice de 0,050 (27/540), espacio lineal relativo y ocupado por cada hilo de la urdimbre, pues lleva 20 hilos en la urdimbre y 18 en la trama por centímetro lineal. Que un tejido lleve menor número de hilos en la dirección de las tramas es lo normal, pues éstas penetran con mayor dificultad en el espacio ya que tienen que entrelazarse con las urdimbres y vencer, por lo tanto, la resistencia que éstas ejercen. Este corporal tiene dobleces muy marcados - uno vertical y dos transversales- por haber estado plegado con el fin de reducir su tamaño, el necesario para poder embutirlo en un relicario en que estuvo guardado hasta hace muy poco tiempo.

Corporal $D$ (Monasterio de Salamanca). Presenta un tamaño más pequeño que el anterior y tiene forma rectangular $(26,5 \times 30,5 \mathrm{cms})$. Parece que en su origen tuvo dimensiones semejantes al anterior, reduciéndose en su longitud por haberse cortado una tira para obtener reliquias. Este corporal está deteriorado, existiendo en su parte central zonas donde el lino ha desaparecido, tanto en las urdimbres como en las tramas. El tejido también es de lino, con un tramado de tafetán cuyo índice de densidad es de 0,045 (26,5/583), pues lleva en la urdimbre 22 hilos y 27 en la trama, por centímetro lineal. Este tejido es más tupido y denso que el del corporal $C$. La diferencia de hilos en la trama con respecto a la urdimbre es menos acusada pero la situación es inversa porque el corporal $C$, más ralo en el tendido de urdimbres, lleva más juntas las hebras de la trama; y el corporal 
$D$, que tiene mayor número de urdimbres en un espacio casi igual, lleva menor número de tramas al ir más separadas. Esto provoca la falsa apariencia de igualdad que ofrecen a la vista ambos tejidos cuando no se recurre a métodos científicos de obtención de índices y solamente nos fiamos de la información por simple observación visual. El corporal $D$ también presenta tres dobleces, dispuestos en la misma forma que el corporal anterior y que obedecen a la misma razón, la de haber sido guardado en el mismo relicario.

De todo lo anterior podemos deducir que ambos corporales, $C$ y $D$, presentan tejidos que han sido labrados por la misma mano o persona, dada la similitud de su traza y textura. Tienen un mismo origen técnico, es decir, se tejieron en el mismo telar y probablemente proceden del mismo cerro o hilada de lino ${ }^{25}$. Puede estimarse que son oriundos de un mismo lugar y que ambos llegaron a España por la misma vía.

Del análisis técnico podemos obtener la conclusión siguiente: los tejidos de lino de los cuatro corporales son diferentes, aunque alguno de ellos sea más semejante a otro. Esta afirmación surge del indicador de densidad y de espacio lineal, factor muy decisivo, como puede verse en la tabla siguiente de resultados:

TABLA DE INDICADORES DE DENSIDAD Y DE ESPACIO LINEAL

\begin{tabular}{|c|c|c|c|c|}
\hline & \multicolumn{2}{|c|}{ Indicadores de densidad } & \multirow[t]{2}{*}{$\begin{array}{l}\text { Núm. total de bilos } \\
\text { en tend. de urd. }\end{array}$} & \multirow[t]{2}{*}{$\begin{array}{l}\text { Indicador } \\
\text { espacial }\end{array}$} \\
\hline & $\begin{array}{l}\text { Nüm. bilos } / \mathrm{cm} \text {. } \\
\text { en urdimbre }\end{array}$ & $\begin{array}{l}\text { Nüm. bilos } / \mathrm{cm} \text {. } \\
\text { en trama }\end{array}$ & & \\
\hline Zamora: & & & & \\
\hline $\begin{array}{l}\text { Corporal } A \\
(27 \times 25 \mathrm{cms} .)\end{array}$ & 33 hilos & 25 hilos & 990 & $30 / 990=0,033$ \\
\hline $\begin{array}{l}\text { Corporal } B \\
(26 \times 26 \mathrm{cms} .)\end{array}$ & 37 hilos & 34 hilos & 1020 & $30 / 1020=0,029$ \\
\hline Salamanca: & 20 bilos & 18 biloc & 540 & $27 / 540=0.050$ \\
\hline$(36 \times 27 \mathrm{cms})$ & 20 nilos & $18 \mathrm{nilos}$ & 340 & $21 / 340-0,030$ \\
\hline $\begin{array}{l}\text { Corporal } D \\
(30,5 \times 26,5 \mathrm{cms} .)\end{array}$ & 22 hilos & 17 hilos & 583 & $26,5 / 583=0,045$ \\
\hline
\end{tabular}

(a) Estos cocientes o indicadores representan el espacio relativo ocupado por un hilo, es decir, no sólo contienen el espacio real sino también parte del espacio vacío entre dos hilos. Esta es otra forma de expresar la densidad del tejido, en la que juegan el grosor del hilo, lo apretado o ralo de su tramado y la regular disposición del tendido total.

${ }^{25}$ Cerro, en artes textiles, hace referencia al manojo de lino o cánamo obtenido después de las primeras labores de limpieza. 
Si comparamos los resultados numéricos dispuestos en la anterior tabla deducimos lo siguiente: el tejido del corporal $A$ es flojo y ralo, de tramado más irregular, presentando notable diferencia entre la densidad de la urdimbre y la de la trama. Las fibras son mucho más finas y el indicador espacial es considerablemente menor, aunque el número de hilos es casi doble, debiéndose el resultado a la finura con que se han hilado. El corporal $B$ presenta un buen equilibrio en la densidad de urdimbres y tramas, dando por ello un tejido homogéneo, apretado y cerrado, de hilada de mediana torsión, flexible y de regular tramado. El indicador espacial es el más bajo de los cuatro, debido a lo compacto de su textura. El corporal $C$ presenta una torsión de grado medio en sus fibras, de grosor uniforme, tramado homogéneo, flexibilidad, con una densidad sensiblemente igual en la urdimbre que en la trama. El indicador espacial del tendido de urdimbre es el mayor de los cuatro tejidos, debido al grosor del hilo y al número de hilos tendidos. El corporal $D$, en apariencia igual al anterior, presenta diferencia mayor entre la densidad de la urdimbre y de la trama. El indicador espacial es menor, lo que señala que el tejido es más grueso pero mantiene las características de homogeneidad y flexibilidad con poca diferencia del anterior; su torsión es también de grado medio.

4.-Función. Los corporales forman parte del recado de la misa, conjunto de objetos que se preparan antes de comenzar y hacen referencia, esencialmente, al cáliz, los corporales, la patena, la hijuela, la palia y el cubrecáliz.

El corporal fue, desde su origen, un lienzo o pequeño mantel que se extiende en el altar, en el mismo lugar del ara, para poner sobre él la hostia y el cáliz. Alcanza, aproximadamente, 40 centímetros de lado, es liso, no lleva adornos y, generalmente, le bordea un encaje. Siempre se usaron dos piezas o corporales para la liturgia de la misa, por eso se aplica el grado de plural incluso cuando se habla de uno solo. En inventarios eclesiásticos, en relaciones de objetos en las cartas de fundaciones de iglesias, en las declaraciones de donaciones de reyes, en las descripciones y recuentos de ornamentos de capillas palaciegas, etc, aparece con frecuencia la cita de "aras con sus corporales", lo que nos indica que el corporal fue el primer mantel o sabanilla de altar que se utilizó. Su forma cuadrada responde a la del ara y surge de una adaptación funcional o de utilidad, la de cubrir la piedra de ésta. El P. Villanueva ${ }^{26}$ sitúa los corporales entre los ornamentos que sirven de

\footnotetext{
26 Op. cit., p. 71.
} 
adorno para el altar. Pero estimo que su función inicial o primordial, que esencialmente conservan, es de utilidad, pues el cubrir la piedra del ara buscaba mayor limpieza y dignidad ya que desde el comienzo de la misa hasta después de la comunión, es decir, desde el ofertorio hasta la comunión, se colocaba sobre él el pan que había de consagrarse y el cáliz con el vino. Posteriormente, al ampliarse la mesa del altar, en la que queda integrada el ara o verdadero altar, empezaron a utilizarse manteles de mayor tamaño y los corporales se dispusieron sobre éstos, en el mismo lugar del ara y ya no en contacto directo con la misma. Posiblemente, por este mismo hecho, se prescindió a veces de uno de ellos colocándose solamente uno sobre la sabanilla que cubría ara y mesa de forma cumplida. Al paso de los tiempos, los corporales fueron ornamentándose añadiendo a su función utilitaria la de adornar el altar, pero esto lo cumplen de forma muy secundaria.

Los cuatro corporales regalados por Santa Clara a los Monasterios de Clarisas de Zamora y Salamanca sin duda estuvieron al servicio del altar como lo atestigua el deterioro que sufren, aumentado por el lavado frecuente que se hacía de estas piezas. Posteriormente, se han reservado como reliquias.

5.-Aspectos artísticos. El corporal, dada su función utilitaria de cubrir el ara, no ha sido objeto de arte ordinariamente. Con todo, los corporales se fueron adornando, especialmente a partir del siglo XVI, llegando a ser piezas muy ricas por su fino tejido de lino y guarnición. En inventarios eclesiásticos espanoles de esta época se recogen las siguientes reseñas: "de holanda labrados con cadeneta brocalada, mezclado el oro y el color verde..., "de holanda labrados de punto real de oro y matices de colores de los de Ciudad Real...", "labrados en oro y plata con cadeneta abrocalada..., "de holanda rica con sus hijuelas y palias guarnecidos todos con franjuelas de oro y algunos con argentería...", "de holanda guarnecidos con randillas blancas" ${ }^{2-}$. De la Capilla del Condestable (Burgos) se recogen las siguientes citas: "los hay ricos de holanda, labrados de cadeneta brocalada de verde y oro, tales los que dio dona Luisa de Velasco y Ribero; labrados de punto real de oro y matices de colores de los de Ciudad Rodrigo de Don Lorenzo Fernández, gobernador que fue de este obispado; labrados en oro y plata de cadeneta abrocalada, regalo de don Juan Ruiz de Santa María, capellán mayor de dicha capilla" ${ }^{28}$. En el inventario del año 1589 de los Franciscanos de Mondragón, se citan: uunos corporales

\footnotetext{
$=\quad$ Op. cit.. pp. 290 y 295.

28 Idem. p. 201.
} 
riquísimos del franciscano Segura, corporales de holanda guarnecidos de franja de oro" ${ }^{29}$. Todas las citas demuestran que los corporales fueron objeto de ricas ornamentaciones, transformándose en piezas artísticas y utilizando para ello metales preciosos, sedas de colores y puntos técnicos complicados y bordados. También se adornan con franjuelas de metales que pueden ser labores de pasamanería o encajes. No faltan las labores de randas o calados sobre la misma tela.

Como elemento complementario de los corporales está la llamada bolsa o funda de los corporales. Generalmente formada por dos hojas de cartón o cartulina fuerte, de forma cuadrada, unidas por uno de sus lados y forradas con ricos tejidos, los correspondientes al terno que se ha de utilizar en cada fiesta litúrgica. La bolsa los proteje y se coloca sobre el cáliz, una vez puesto el paño llamado cubrecáliz o velo de cáliz. La bolsa cumple la función de guardar los corporales cuando no han de estar desplegados.

Los cuatro corporales objeto del presente estudio llevan el tejido de lino y sin adorno alguno en la superficie. Pero van orlados de bellas guarniciones de encaje.

Los corporales $A$ y $B$ (Monasterio de Zamora) van bordeados de un mismo tipo de encaje, un bellísimo modelo del género numérico o de doce bolillos, realizado en lino blanco. Es un diseño propio del siglo xviI, característico de la escuela catalana, aunque por el estilo de su composición podría situarse ya en el siglo XVIII al atisbar rasgos del más puro y fino rococó ${ }^{30}$. Probablemente estos corporales recibieron otro tipo de guarniciones, procedentes del monasterio fundacional, posiblemente de deshilado o encaje, labores propias de la época. Deteriorada la guarnición, las religiosas de Zamora decidieron adornarlos nuevamente y eligieron para ello un encaje de bolillos de tipo numérico, de gran belleza por las abundantes curvas e involuciones que lo caracterizan. Puede asegurarse que este encaje se realizó en la sala de labor del convento, según tradición, pues en ella se obraron todo tipo de labores y encajes. Por lo que antecede puede asegurarse que solamente el tejido es lo realizado por Santa Clara.

Los corporales $C$ y $D$ (Monasterio de Salamanca) llevan también en todo su entorno sendos encajes aunque de estilo distinto. El corporal $C$ va adornado con un encaje del género de bolillos denominado punto de $E_{s p a n ̃ a}{ }^{31}$. Está realizado únicamente con hilillo de oro. Reproduce un

$29 \quad$ Idem. pp. 212 y 213.

30 M. ${ }^{a}$ Ángeles GONZÁlez MENA, Catálogo de Encajes, (Madrid: Instituto Valencia de Don Juan, 1976), pp. 104-116.

31 Idem, pp. 253-273. 
antiguo modelo castellano de raíz mudéjar en el que dos cintas de lacería, que se mueven en zig-zag, forman rombos sucesivos en los que se inscriben milanos de rombillos y barras. La corona del encaje se remata con arquería de ondas rebajadas cuyo tramado forma picos. Este encaje fue aplicado recientemente, habiendo tenido antes otro de estilo mecánico y género Binche que, probablemente, sustituyó a la ornamentación original.

El corporal $D$ también está rodeado de un encaje del genéro anillado de Valladolid, encaje a la aguja, propio de los siglos XVI y XVII y de origen castellano, de donde deriva su nombre, en cuyos monasterios de religiosas se realizaron bellísimas labores para ornamentos litúrgicos. Su mayor desarrollo debió producirse en las salas de labor de los conventos carmeli$\operatorname{tanos}^{32}$. El encaje de este corpo-

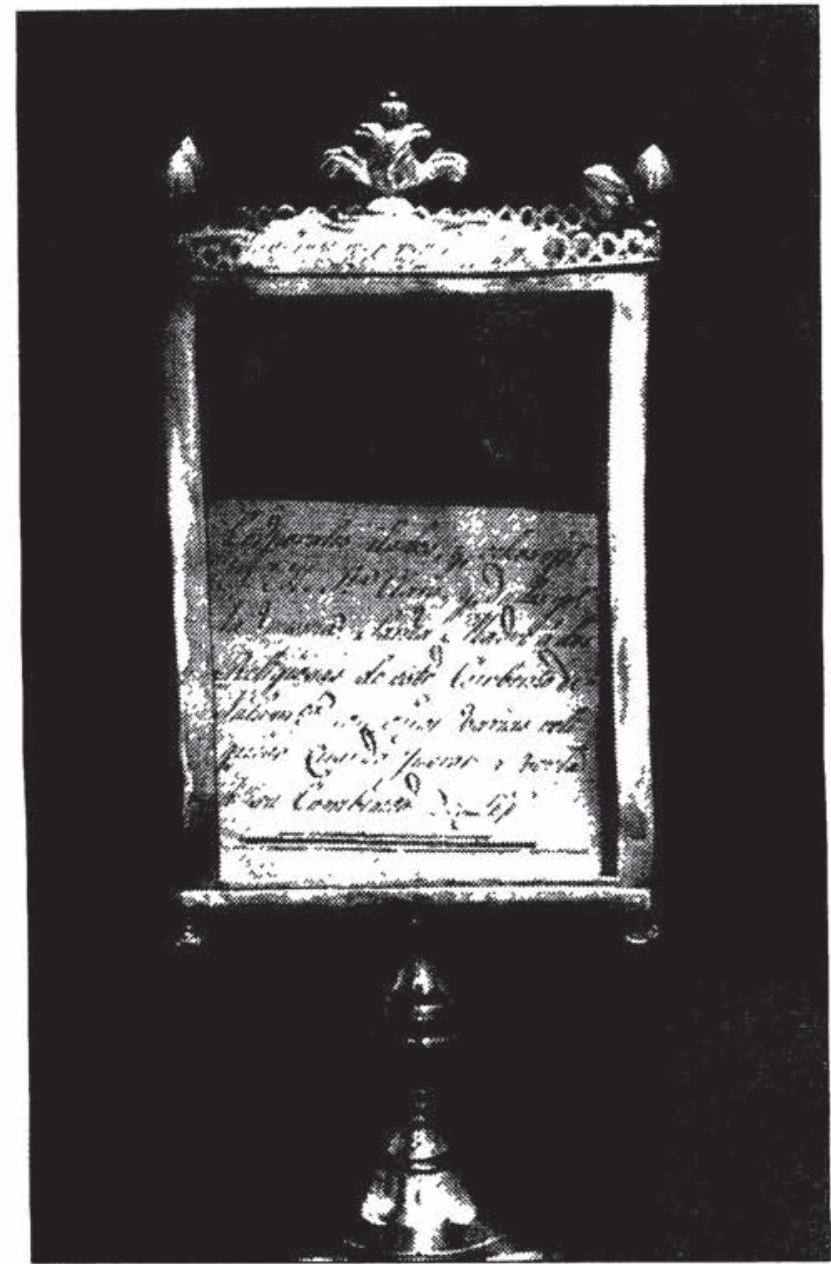

FIG. 4.-Relicario de metal dorado, en el que se conservan los dos corporales, $C$ y $D$, del Monasterio de Salamanca. Sencilla y elegante interpretación de formas renacientes con talante barroco. En su interior puede verse el manuscrito que atribuye la hechura de dichos corporales a Santa Clara de Asís.

ral salmantino está formado por piezas independientes y en dos modelos: el dispuesto en los ángulos, formado por ocho piezas con seda "flor" de color asalmonado y metal dorado, muy fino. El segundo modelo bordea los lados, realizados también con seda de la misma calidad en colores rosa y verde y hebra del mismo metal, disponiéndose en ritmo alternado de colores.

Los encajes de estos dos corporales son reproducciones de modelos antiguos, realizados hacia el año 1946, según se nos indicó, por jóvenes de unos 16 años. Inicialmente se manufacturaron para ornamentar un cubrecopón; la labor no fue terminada y ahora no pueden tener mejor

32 Idem, pp. 391-405. Y además, de la misma autora: -Un encaje castellano: el Frisado de Valladolid., Narria (1985), pp. 10-13. 
aplicación. Hacemos las mismas reflexiones que en los corporales del Monasterio de Zamora. En su origen pudieron haber estado adornados con otras labores de época medieval que por la acción del uso y del lavado desaparecerían. Los encajes descritos, que actualmente los guarnecen, han sido aplicados recientemente.

6.-Valores simbólicos. Los corporales, dada su función y aplicación en la celebración de la misa, al igual que las palias e hijuelas, eran piezas de regalo a las iglesias por parte de reinas, damas, mujeres piadosas que ellas mismas confeccionaban ${ }^{33}$. Esto hacían también las religiosas pues realizaban todo género de bordados y encajes, así como ornamentos sagrados siguiendo el principio del ora et labora. No es de extrañar que Santa Clara ocupara gran parte del día, aun estando enferma, en hilar y tejer lino para ornamentos y proveer así a las iglesias de sus propios monasterios y conventos. Estas piezas que habían de estar en contacto con las sagradas especies ya tenían cierto valor simbólico y ritual.

Por otro lado, todo objeto, artístico o utilitario, desde el momento que pierde la función principal para la que fue hecho y recibe un nuevo valor de comunicación, cuando de objeto útil pasa a objeto símbolo es porque se le ha investido de nuevos valores, concedidos por los cambios sociales o de pensamiento. La santa veneración que las religiosas sienten por su fundadora, Santa Clara, sin duda les ha llevado a elevar a calidad de símbolos muchos de los objetos que ella utilizó, tocó o realizó. Por ello, estos cuatro corporales han sido transformados en símbolos, en objetos extraordinarios y singulares, en unas reliquias que contienen un lenguaje del pasado de carácter religioso, al ser realizados por las manos de una santa. Estos cuatro corporales revestidos de nueva función, separados del culto de la misa, han sido reservados y guardados con especial cuidado para que se conserven el mayor tiempo posible y así poder recordar, a través de su existencia, la laboriosidad, la piedad y la religiosidad de Santa Clara. El simbolismo aumenta si se ponen a la veneración de los visitantes del monasterio alcanzando una dimen-

33 Hay numerosas citas en las que reinas y damas regalan piezas de su propia indumentaria, de parada o aparato, para que sean transformadas en casullas, paños de hombros, estolas, etc., y también hacían paños de altar de lino. Los Trinitarios Descalzos, en la persona de fray Juan Bautista, fundan en Valladolid la octava casa reformada, en septiembre de 1605 . Es inaugurada con la mayor solemnidad a pesar de ser un convento pequeño. El rey Felipe III tomó gran interés por esta Orden de frailes y también se interesó el Duque de Lerma. Para el día de la inauguración, la propia reina había confeccionado unos corporales (Juan PujANA, San Juan Bautista de la Concepción. Reformador de la Orden Trinitaria, Roma, 1975, p. 43). 
sión social. Uno de los corporales se ha reducido para realizar reliquias (corporal $D$ del Monasterio de Salamanca) habiéndosele privado de una franja.

Los corporales custodiados en el monasterio de Salamanca han sido considerados como verdaderas reliquias e incluso están guardados en un relicario, lo que confirma esta intención simbólica hacia ellos. Dicho relicario es de plata y se mandó labrar para este fin. Consta de tres partes: peana, urna y corona. La peana $o$ astil es de base circular con anillo inciso que determina una zona convexa rematada por un reborde recto y plano sobre el que se apoya. En el centro destaca un airoso nudo flanqueado por molduras que disminuyen de diámetro. La urna o estuche, en forma de caja, está constituida por cuatro marcos lisos de metal con vidrieras planas para dejar visibles los corporales y la leyenda manuscrita que les acompaña. La corona remata el relicario con cenefa calada de figurillas ovaladas unidas entre sí tangencialmente. En los ángulos se asientan botones y en el centro, un florón que alberga una bellota o perinola. En los ángulos inferiores, unos tornillos articulan la apertura y cierre del relicario.

Los elementos estilísticos de este relicario pertenecen al lenguaje clásico renaciente pero el artista los ha utilizado con una metodología barroca. En primer lugar, ha intentado reproducir, de forma simplificada, un modelo de templete propio de las custodias de esta época, en segundo lugar, los elementos de la corona han sido ordenados con marcada sencillez simétrica pero con ritmo repetido. Junto a los corporales y dentro del relicario se ha conservado una leyenda manuscrita de elegante letra humanística, propia del último tercio del siglo xviI o inicios del XviI ${ }^{34}$, que dice:

- Corporales ilados y echos pr / N.M. Sta. Clara y dados pr. / la misma Santa Madre á dos / Religiosas de este Combento de / Salam. ${ }^{\text {ca }}$ con otras varias reli / quias cuando fueron á verla / á su Combento de Sis* [sic].

34 He consultado a Don Gregorio de Andrés, notable especialista de manuscritos, quien los ha estimado como de esta época. Pero después de realizada esta consulta, la Madre Secretaria del Monasterio de Santa Clara de Salamanca me envía una nota en la que se afirma que este tipo de letra humanística hay que situarla a fines del siglo XVIII y principios del XIX, según informe procedente del Archivo Histórico Provincial de dicha ciudad. Como la diferencia que existe entre entre ambas dataciones es nada menos que de un siglo, decide hacer una nueva consulta: en la Cátedra de Paleografía Diplomática de la Universidad Complutense (Madrid) han opinado que se trata de un tipo de letra que se extiende desde fines del siglo xvII a todo el XviII, sin grandes variaciones, por lo que conviene situarla dentro de este último siglo. 
Esta leyenda fue escrita, sin duda, para ser incluida en el relicario pues se adapta perfectamente a sus medidas. Puede concluirse que los dos corresponden a la misma época, pudiendo datarse como decíamos en el último tercio del siglo xvir, aunque no necesariamente tuvo que haberse escrito la leyenda en el mismo momento de estrenarse el relicario para su función de guardar los corporales.

\section{CONCLUSIONES FINALES}

La datación de los cuatro corporales puede situarse dentro del siglo XIII, entre 1237 y 1253 . En este año muere la Santa, el 11 de agosto, habiendo estado enferma los últimos años. Según escritos reseñados anteriormente, los corporales del Monasterio de Zamora pudieron llegar al monasterio en el año 1237, traídos desde Asís por Dominga, abadesa entonces en la Comunidad de dicho monasterio. Los corporales del Monasterio de Salamanca pudieron llegar a esta ciudad en el mismo año, época en que la hermana Urraca se desplazó a Asís en pereginación.

No debe extrañar su buen estado de conservación por ser un tejido que data de la Edad Media, pues se han rescatado piezas y fragmentos de esta misma época y de tiempos más antiguos procedentes de enterramientos reales españoles y europeos, así como de monumentos funerarios egipcios, con antigüedad milenaria, y de yacimientos neolíticos de centroeuropa, demostrándose la calidad del tejido de lino. Se ha comprobado que este género de tejido, en unas mínimas condiciones ambientales, puede conservarse durante muchos años y aún siglos, cualidad reconocida sobre otros tejidos más vulnerables, como los de lana y seda.

En orden al contenido de la nota que acompaña a los corporales de Salamanca, conservados con ella en un relicario, estimo conveniente aclarar la frase de: "fueron ilados y hechos por Santa Clara". En la primera voz claramente se incluye la acción de transformar el copo de lino en hilo; pero en la palabra bechos, de caracter más genérico, ¿qué otras fases pueden incluirse?, ¿todas las que fueran precisas para darlos por acabados de forma total, como tejerlos, coserlos y guarnecerlos?. Anteriormente, el P. Omaechevarría ${ }^{35}$ ha expuesto fragmentos de documentos escritos en que se presentan declaraciones de testigos presenciales, y todas ellas, por unanimidad, coinciden en que la Santa Madre hiló el lino; algunas añaden que también los tejió en algunas ocasiones ${ }^{36}$. La confección de los mismos

35 Escritos de Santa Clara y Documentos Completos (Madrid; BAC, 1982), pp. 70, $75,91,98,122$ y 163.

36 .También dijo que en el tiempo que estuvo enferma [...] se hacía incorporar, y se sentaba sostenida con almohadas, e hilaba; y tanto, que de esta tela hizo confeccio- 
en la fase de cosido o rematado solía ser operación realizada por las hermanas religiosas.

Asimismo, se afirma en diversas declaraciones de los testigos que Santa Clara mandó confeccionar bolsas para guardarlos y enviarlos a las distinguidas iglesias. Estos cuatro corporales tuvieron que llegar a España en sendas bolsas o fundas de corporales, como era habitual, costumbre que aún perdura. Se dice en los documentos escritos ${ }^{37}$ que fueron hechas con sedas y paños preciosos. Por ser estos materiales más endebles a la acción del tiempo y de los agentes ambientales no han llegado a nosotros; en ambos monasterios, de Zamora y Salamanca, no se conservan.

Otra cuestión es si venían con alguna decoración añadida. Observados los corporales en su propia naturaleza y forma, conservan las orillas laterales en dos de sus lados, propias del tramado sobre las urdimbres, y los otros dos extremos van rematados a dobladillo por puntos de sencilla costura. No creo que así fueran acabados de forma total, pues aunque era proverbial y preceptiva la pobreza en los conventos de clarisas, bien es cierto que para el altar no escatimaban lo necesario, sobre todo, si dependía de la labor de sus propias manos. Estimo que probablemente pudieron haber estado decorados con algún sencillo encaje o labor "a la aguja", como la conocida de reticella, hechura calada muy antigua en Italia, o algún sencillo encaje de bolillos.

Por último, el hecho de que los cuatro corporales no coincidan en el tamaño y calidad del tejido, no impide que constituyan pareja en el momento de ser utilizados en las ceremonias rituales, pues no era condición necesaria. El culto exigía que hubiera dos corporales pero nunca que fueran idénticos, aunque las rúbricas señalaban que el de abajo fuera ligeramente mayor.

\author{
M.^ÁNGeles GonZÁLEZ Mena (I Y III) \\ Museo Pedagógico Textil \\ FR. IGNACIO OMAECHEVARRÍA (II) \\ O. F. M.
}

\begin{abstract}
nar corporales [...] que le había visto hilar y hacer la tela [...] (Declaraciones de sor Pacífica, p. 70). De esta manera consiguió que se hicieran, de la tela de lino preparada con su labor y arte, muchos corporales para el sacrificio del altar... (Declaraciones de Juan Ventura. En Escritos de Santa Clara y Documentos Completos, p. 122.

3. En la misma obra se recogen los siguientes datos: *Pero añadió que hizo elaborar también unas fundas de cartón para guardarlos y que las hizo forrar de seda y los hizo bendecir por el obispo* (Declaraciones de sor Bienvenida, p. 75) [...] y fundas para guardarlos, guarnecidas de seda y paño precioso (declaraciones de sor Cecilia, p. 91) [...] que envueltos en bolsas de seda o púrpura..., p. 163.
\end{abstract}


Se estudia la autenticidad de cuatro corporales atribuidos a Santa Clara de Asís, que se conservan en dos monasterios de clarisas en Salamanca y Zamora. La costumbre de regalar a sus monjas esta pieza litúrgica queda probada por documentación privada y oficial de la época. Se analiza su función, fábrica y técnicas, así como el paso de objeto útil a pieza de veneración, convertida en reliquia que se adorna con encajes y se expone en relicarios.

This article is concerned with the authenticity of the four "corporales" supossedly owned by Saint Claire of Asis today preserved in two monasteries of Salamanca and Zamora. The tradition of giving the nuns as a present this sort of liturgical pieces is well documented through both private and public sources. The function, fabric and tecniques of these "corporales" are also studied, as well as the shift from being useful objects to be considered as relics decorated with embroideries and exhibited in reliquaries. 